\title{
Observational Study on a Mindfulness Training for Smokers within a Smoking Cessation Program
}

\author{
James M. Davis ${ }^{1,2}$ • Simon B. Goldberg ${ }^{3} \cdot$ Kelly S. Angel $^{4} \cdot$ Rachel H. Silver $^{5}$ • \\ Emily A. Kragel ${ }^{5}$ - Delaney J. Lagrew ${ }^{5}$
}

(C) Springer Science+Business Media New York 2017

\begin{abstract}
Mindfulness is a skill of intentionally directing one's attention to emotions, thoughts, or physical sensations with an open-minded, non-judgmental attitude. Mindfulness can enable a person to experience challenging feelings or situations without reacting impulsively or automatically. Mindfulness training may be provided to smokers to help them manage smoking triggers, urges, stress, or negative emotions without smoking. Randomized controlled trials have now shown that mindfulness training for smokers (MTS) yields smoking abstinence rates that are equal to or higher than matched behavioral treatments. We describe a comparative observational study on MTS within an ongoing clinical program. The study was conducted with a naturalistic design and utilized no procedures or evaluations beyond those already employed in clinical practice. All participants were advised to use FDA-approved smoking cessation medications and were provided with a choice of two behavioral treatments-MTS (selfpay) or the Wisconsin Tobacco Quit Line (WTQL) (free). Over a 12-month study period, 181 clinic patients enrolled; $65.75 \%$ (119) choose MTS and $34.25 \%$ (62) choose WTQL. MTS compared to WTQL treatment initiators showed significantly higher biochemically confirmed
\end{abstract}

James M. Davis

james.m.davis@duke.edu

Department of Medicine, Duke University, Durham, NC, USA

2 Duke Center for Smoking Cessation, 2424 Erwin Road, Suite 201, Durham, NC 2751, USA

3 Department of Counseling Psychology, University of Wisconsin, Madison, WI, USA

4 Hospital Medicine, Meriter Hospital, Madison, WI, USA

5 Duke Cancer Institute, Duke University, Durham, NC, USA 7-day point prevalence smoking abstinence at 2 weeks postquit attempt $(\mathrm{MTS}=47.00 \%, \mathrm{QL}=24.52 \%, p=.011$, $\mathrm{OR}=2.71)$. Intent-to-treat analysis showed similar outcomes $(p=.019, \mathrm{OR}=2.45)$. The study provides evidence that MTS provided within clinical program leads to similar outcomes as found in randomized controlled trials. The strategic use of MTS within a smoking cessation program is discussed.

Keywords Mindfulness $\cdot$ Smoking $\cdot$ Smoker $\cdot$ Tobacco $\cdot$ Abstinence $\cdot$ Mindfulness training

\section{Introduction}

Tobacco use continues to be the number one cause of preventable morbidity and mortality in the USA (Centers for Disease Control and Prevention 2008). Smoking is a major cause of lung and heart disease (Centers for Disease Control and Prevention 2008) and is now associated with 13 types of cancer (Alberg et al. 2014), and as much as two-thirds of smoker will die from a smoking-related illness. The population of smokers in the USA has changed substantially over recent decades, with smokers today showing greater nicotine dependence (Cokkinides et al. 2009; Goodwin et al. 2009), higher incidence of psychiatric diagnosis (Annamalai et al. 2015; Centers for Disease Control and Prevention 2013), more failed quit attempts (Chaiton et al. 2016; Hughes 2011; Irvin et al. 2003), and greater resistance to available treatments (Ip et al. 2012; Irvin et al. 2003). Over 50\% of smokers attempt to quit smoking each year (Centers for Disease Control and Prevention 2011), but under 5\% of unassisted quit attempts and only $10 \%$ of assisted quit attempts lead to sustained abstinence (Fiore et al. 2008). This growing treatment resistance in the face of profound morbidity and mortality has created a need for more effective therapies (Brandon 2001; Chaiton 
et al. 2008). In response to this problem, there has been substantive innovation in tobacco dependence pharmacotherapies (Fiore et al. 2008; Stead et al. 2008), but comparatively little innovation in the development of behavioral therapies with the notable exceptions of Motivational Interviewing (Lai et al. 2010) and Acceptance and Commitment Therapy (ACT) (Bricker and Tollison 2011; Gifford et al. 2011).

Mindfulness in its simplest form is a cognitive skill that can be taught with only brief instruction (e.g. $5 \mathrm{~min}$ ) and practice (e.g. $30 \mathrm{~min}$ ) with demonstrable reduction of smoking urges and associated brain activity (Westbrook et al. 2013). Mindfulness might be described as mentally disengaging from automatic or reactive behavior to become aware of our experiences, thoughts, or feelings as they occur so that we may respond from a perspective that is engaged, open-minded, and non-judgmental (Kabat-Zinn and Hanh 1990; Segal et al. 2002). It does not entail changing what we are doing or thinking, but instead bringing intentional awareness and acceptance to ordinary moment-to-moment experience. This acceptance-based approach runs counter-to-cognitive approaches in which an individual "strives to overcome" a negative emotion or thought (Beck 1979; Wolpe 1990). In people who smoke, the act of challenging an urge can paradoxically lead to a prolonged urge (Rogojanski et al. 2011; Whitfield 2006). This finding has led to the exploration of acceptancebased cognitive strategies to overcome tobacco dependence. Studies on mindfulness training have suggested reductions on automatic behavior (Witkiewitz et al. 2014), impulsive reactions (Way et al. 2010), physiologic stress (Goldberg et al. 2014; Grossman et al. 2004), anxiety (Creswell et al. 2007; Hofmann et al. 2010; Koszycki et al. 2007), and depression (Teasdale et al. 1995).

Mindfulness training was first studied as a treatment for smokers, in a pilot study, which found that time spent practicing mindfulness meditation was associated with smoking abstinence (Davis et al. 2007). Since then, Mindfulness Training for Smokers (MTS) and similar interventions have been evaluated in a number of randomized controlled trials (RCTs) (Brewer et al. 2011; Davis et al. 2013, 2014a, b; Vidrine et al. 2016). A recent meta-analysis across multiple RCTs showed that abstinence rates for MTS were almost twice that of matched behavioral controls $(\mathrm{RR}=1.88$ (95\% CI 1.04-3.40)) (Oikonomou et al. 2016). Studies on MTS and similar interventions have shown a significant association between daily meditation practice time and smoking abstinence (Davis et al. 2014a), as well as significant reductions on measures of stress, negative affect, and urge to smoke compared to controls (Brewer et al. 2011; Davis et al. 2014a, b). Neuroimaging and cognitive processing studies have led to two compelling models for how mindfulness may function therapeutically within an addiction (Brewer et al. 2013; Elwafi et al. 2013; Garland et al. 2013). In Brewer et al.'s (2011) model, mindful attention enhances activity in the pre-frontal cortex, activating top-down regulatory processes with interruption of brain pathways associated with emotion and cue-elicited reward-based behavior. Garland et al. (2013) expanded on this model, proposing that mindfulness practice also increases functional connectivity between the pre-frontal cortex and subcortical networks involved in salience of and response to appetitive cues. In this model, greater top-down functional connectivity potentiates greater capacity to respond to drug cues through pre-frontal rather than sub-cortical processes (Garland et al. 2013).

In an RCT, Davis et al. (2014a) assessed smokers randomized to MTS vs. the Wisconsin Tobacco Quit Line (WTQL); the study showed signifcantly higher abstinence rates in MTS at 4 weeks post-quit $(\mathrm{MTS}=45.8 \%$ vs. $\mathrm{WTQL}=25.4 \%$ $(p=0.02))$ and 24 weeks post-quit $(\mathrm{MTS}=38.7 \%$ vs. WTQL $=20.6 \%$; $(p=0.05)$ ). The study utilized design elements commonly employed in RCTs including recruitment through advertisements, use of exclusion criteria, 1:1 randomized group allocation, free behavioral treatment and medications (4 weeks of NRT), participant payment, use of objective and self-report measures, and multiple study visits with research staff. Randomized control trials (RCTs) are the gold standard for determining the efficacy of medical treatments (Sibbald and Roland 1998). A well-designed RCT will commonly use inclusion/exclusion criteria, participant payment, and free treatment (Weisberg et al. 2009) to experimentally isolate specific therapeutic ingredients and reduce bias (Stolberg et al. 2004). Unfortunately, however, the design elements of RCTs also typically lead to an over-estimation of the effectiveness of a treatment (e.g. stringent exclusion criteria may exclude less motivated and low functioning individuals, free medications help ensure the use of medications, and close oversight by staff increases attendance and outcomes), decreasing the generalizability of results to clinical practice (Moulton 2004; Weiss et al. 2008). After RCTs have established a treatment as efficacious, an important next step is to assess the treatment within a clinical environment (Woolf 2008). In order to bring greater ecological validity to the assessment, it is common to conduct an observational study with a naturalistic design. This approach might include for example no recruitment drive, limited or no inclusion/exclusion criteria, therapies with standard costs, no participant payment, no additional research procedures or evaluations, and limited contact with research staff (McLeod 2015). Testing a new treatment within an observational trial is, however, often neglected, perhaps because observational studies are vulnerable to a number of problems that together lead to smaller treatment effects: Requiring participants to pay for their own treatments can lead to low adherence rates; lack of payment and limited contact with study staff can lead to high attrition (Song and Chung 2010). Although MTS has performed well within clinical trials, it is currently unknown how it might perform in a clinical setting. We do not know what proportion of clinic patients would choose to enroll in MTS, how many classes they might attend, or whether abstinence rates would be similar to those found in clinical trials. 


\section{Method}

\section{Participants}

Study enrollment continued for 12 months, during which all patients seen within the Meriter Smoking Cessation Program were asked if they would provide consent to have their clinic data used for research purposes. All study participants were patients within the Meriter Smoking Cessation Program, and the only criterion for participation in the study was participation in the clinical program. The clinical program enrolled adults (18 and over) seeking treatment for tobacco dependence, with no exclusions. All patients in the clinical program were offered an opportunity to sign consent to have their information used for research purposes and all but two signed consent. Their reasons for not signing consent were not recorded.

\section{Procedure}

Clinic Visits All clinic patients (including study participants) completed a brief clinic-based evaluation including questions on demographics and smoking history. For all clinic patients, smoking status was assessed at the initial visit via exhaled breath carbon monoxide (CO) testing and a 7-day smoking history (Brown et al. 1995). Smoking abstinence was defined as selfreport of no smoking (not even a single puff) in the past 7 days plus a $\mathrm{CO}$ test result of under $7 \mathrm{ppm}$ (National institute for Health and Care Excellence 2010). All clinic patients were scheduled for a return clinic visit 2 weeks after their quit day at which they were asked to repeat $\mathrm{CO}$ breath testing and 7-day smoking history. At the return visit, clinic patients who choose MTS as their behavioral treatment were asked about the amount of time they spent in daily meditation over the last 7 days. The clinic did not administer standardized tests (e.g. on nicotine dependence, depression, anxiety, stress, or alcohol use), and these tests were not administered to study participants.

\section{Choice of Medications and Behavioral Treatment All clinic} patients (including study participants) chose medications and behavioral treatment through a joint decision-making process with the smoking cessation program coordinator. FDAapproved smoking cessation medications were recommended to all patients based on the Clinical Practice Guideline Treating Tobacco Use and Dependence (Fiore et al. 2008) with modifications based on medication intolerance, patient preference, insurance coverage, and cost burden. Primary providers were contacted for all patients (when available) to provide prescriptions. Participants were provided with a choice of two behavioral treatments: Mindfulness Training for Smokers or referral to the Wisconsin Tobacco Quit Line (WTQL) with a directly observed initial call or a referral through the Fax to Quit Program (Kobinsky et al. 2010). A description of each intervention was provided which included information about the required payment for MTS with reimbursement for completers (see below). The Program Coordinator explained that all patients in the clinic should receive some form of behavioral treatment not only that MTS had been more effective for smoking cessation than the WTQL in a randomized trial but also that "it is possible that your results will be different from those found in research." MTS utilized "cost-incentive" pay structure in which patients were required to pay for MTS course enrollment but would then receive full reimbursement through an insurance provider after completion of the course regardless of smoking status (course costs were on a sliding scale). Clinic patients (including participants) were required to acquire medications on their own (via insurance or self-pay), although NRT was provided through the WTQL for participating patients (see below).

MTS Intervention The MTS course provided is a grouptherapy skills training course comprised of seven weekly 21/2-hour classes and a 61/2-hour Quit Day Retreat for a total of $24 \mathrm{~h}$ of instruction. The MTS course is led by instructors certified through completion of the 3-day Teacher Training Course. MTS course materials include an instructional DVD, a manual, and audio CDs. The course follows videobased instruction played during class and provides examplebased education with language appropriate for seventh-grade learners. The MTS course not only contains behavioral tools commonly used in smoking cessation interventions such as planning for the quit day, behavioral strategies for management of triggers and urges, but also included training in mindfulness meditation and mindfulness of smoking triggers, urges, emotions, and thoughts. MTS participants were asked to engage in 15-30 min of daily meditation with the Guided Meditation Audio-Recording and to use mindful attention spontaneously throughout the day to manage stress, emotions, triggers, urges, and other relapse challenges. The Quit Day Retreat follows the fifth class and includes multiple instructor-guided mindfulness exercises to facilitate emersion into the practice of more regular use of mindfulness.

WTQL Intervention The WTQL is operated by Alere Wellbeing (now Optum $®$ ) and is the largest telephonic smoking cessation service provider in the USA. Individuals who called the WTQL received up to five proactive (the coach calls the client) counseling calls from a Quit Coach, access to Web Coach, an interactive web-based program with education and discussion forums, 2 weeks of free nicotine replacement, and printed self-help materials. In addition to proactive calls to smokers, participants were allowed to place an unlimited number of "reactive" calls to the WTQL which provided 24/ 7 call availability. Whenever possible, the WTQL registration call (to Alere Registration Specialist) was made under observation at the smoking cessation clinic to ensure enrollment in services. If the patient did not make an observed call from the 
clinic, a WTQL Fax to Quit Program Referral was placed, initiating registration and proactive calls to the participant.

\section{Measures}

No standardized tests were used in this study. Instead, only demographic information, smoking history, 7-day smoking calendar and carbon monoxide $(\mathrm{CO})$ breath testing were performed. All of these were performed at baseline but only 7-day smoking calendar and $\mathrm{CO}$ testing were performed post-treatment.

\section{Data Analyses}

Data were analyzed using the $\mathrm{R}$ statistical software ( $\mathrm{R}$ Development Core Team 2011). Chi-square $\left(\chi^{2}\right)$ tests were used to compare MTS and WTQL groups on dichotomous variables (e.g. gender, quit status), and odds ratios (OR) were computed using a Fisher's exact test. Independent $t$ tests were used to compare groups on continuous variables (e.g. age, number of years smoked). One-sample $t$ tests were used to compare the number of participants choosing each intervention. Two sample $t$ tests and chi-square tests were used to assess continuous variables including potential association of demographic variables, medication use, and program participation with abstinence. For assessment of smoking status (abstinence vs. relapse), we adhered to the conservative principal that all missing data (e.g. missed return appointment) was coded as "relapsed." Because the study sample was not randomized, conditions for Data Missing at Random (MAR) were not met to allow for multiple imputation to assess missing data.

\section{Results}

\section{Recruitment and Intervention Choice}

Over the 12-month study period, 195 patients came to a clinic visit at the Meriter Smoking Cessation Program and all 195 were offered an opportunity to join the study. Of these, $92.80 \%(n=181)$ provided consent to have their data used for research purposes and were enrolled in the study. Reasons for not joining the study are provided in the consort diagram (Fig. 1). Significantly more participants chose to participate in MTS than WTQL (MTS $=65.75 \%(n=119)$, $\mathrm{WTQL}=34.25 \%(n=62) ; t[180]=4.45, p<.001)$. Based on an interview with the Program Coordinator, the most commonly cited factors leading to the choice of MTS over WTQL were that these participants had already used Quit Line in the past and it was ineffective for them, or that they had tried to quit and failed multiple times and wanted to use the most effective treatment possible (mean number of failed prior quit attempts for the full sample was 5.84).

\section{Baseline Characteristics}

MTS and WTQL groups did not differ on age $(\mathrm{MTS}=51.60$ $[\mathrm{SD}=12.46], \mathrm{WTQL}=51.63[\mathrm{SD}=11.80]$ ), gender $(\mathrm{MTS}=31.93 \%$ male, $\mathrm{WTQL}=41.94 \%$ male $)$, or baseline smoking characteristics (cigarettes per day, years smoked, prior quit attempts; all $p>.10$ ) (Table 1). MTS participants were more likely to be Caucasian (MTS $=93.28 \%$, $\mathrm{WTQL}=74.19 \% ; \chi^{2}[1]=11.30, p<.001$, OR $\left.=4.78\right)$, have education beyond high school $($ MTS $=57.14 \%$, $\left.\mathrm{WTQL}=16.13 \% ; \chi^{2}[1]=26.31, p<.001, \mathrm{OR}=6.86\right)$, and consume more alcoholic drinks per week $(\mathrm{MTS}=1.57$ $[\mathrm{SD}=1.57], \mathrm{WTQL}=0.76[\mathrm{SD}=0.76] ; t[179]=2.56$, $p=.011)$. Baseline variables are provided in Table 1 .

\section{Intervention Adherence}

Enrollment in MTS required payment for the MTS course. Of all MTS enrollees, $84.03 \%(n=100)$ attended at least one class (treatment initiators). Nineteen participants paid for the course but did not attend any classes during the study period. Based on an interview with Program Coordinator, most of these participants (15 of 19) who paid for MTS but did not attend any classes rescheduled their start date to attend the course after the study period (see consort diagram in Fig. 1). It is assumed that some portion of the 15 who paid and rescheduled did in fact attend classes. For this reason, intentto-treat analyses of MTS participants may underestimate the actual percentage of patients who quit smoking, and treatment initiator analysis is also provided. Among WTQL participants, $85.48 \%(n=53)$ completed at least one phone call to the Quit Coach (treatment initiators); the Quit Coach call followed the initial observed call to the Registration Specialist. MTS and WTQL groups did not differ on treatment initiation $\left(\chi^{2}\right.$ $[1]=.002, p=0.969, \mathrm{OR}=0.89)$. Among MTS initiators, $72.00 \%(n=72)$ attended the Quit Day Retreat (defined as treatment completers). There was no comparable method for defining "completion" within the WTQL intervention.

\section{Abstinence Rates}

An analysis of treatment initiators $(n=153)$ on biochemically confirmed 7-day point prevalence smoking abstinence at the 2-week post-quit clinic visit showed MTS abstinence rate $=47.00 \%(n=47), \mathrm{WTQL}$ abstinence rate $=24.52 \%$ $(n=13), \chi^{2}[1]=6.43, p=.011, \mathrm{OR}=2.71$. An intent-totreat analysis $(n=181)$ of the same showed MTS abstinence rate $=39.50 \%(n=47), \mathrm{WTQL}$ abstinence rate $=20.97 \%$ $(n=13), \chi^{2}[1]=5.51, p=.019, \mathrm{OR}=2.45$. Abstinence rates for the MTS course completers were $65.30 \%(n=47)$, with no comparable definition of completion for WTQL. 


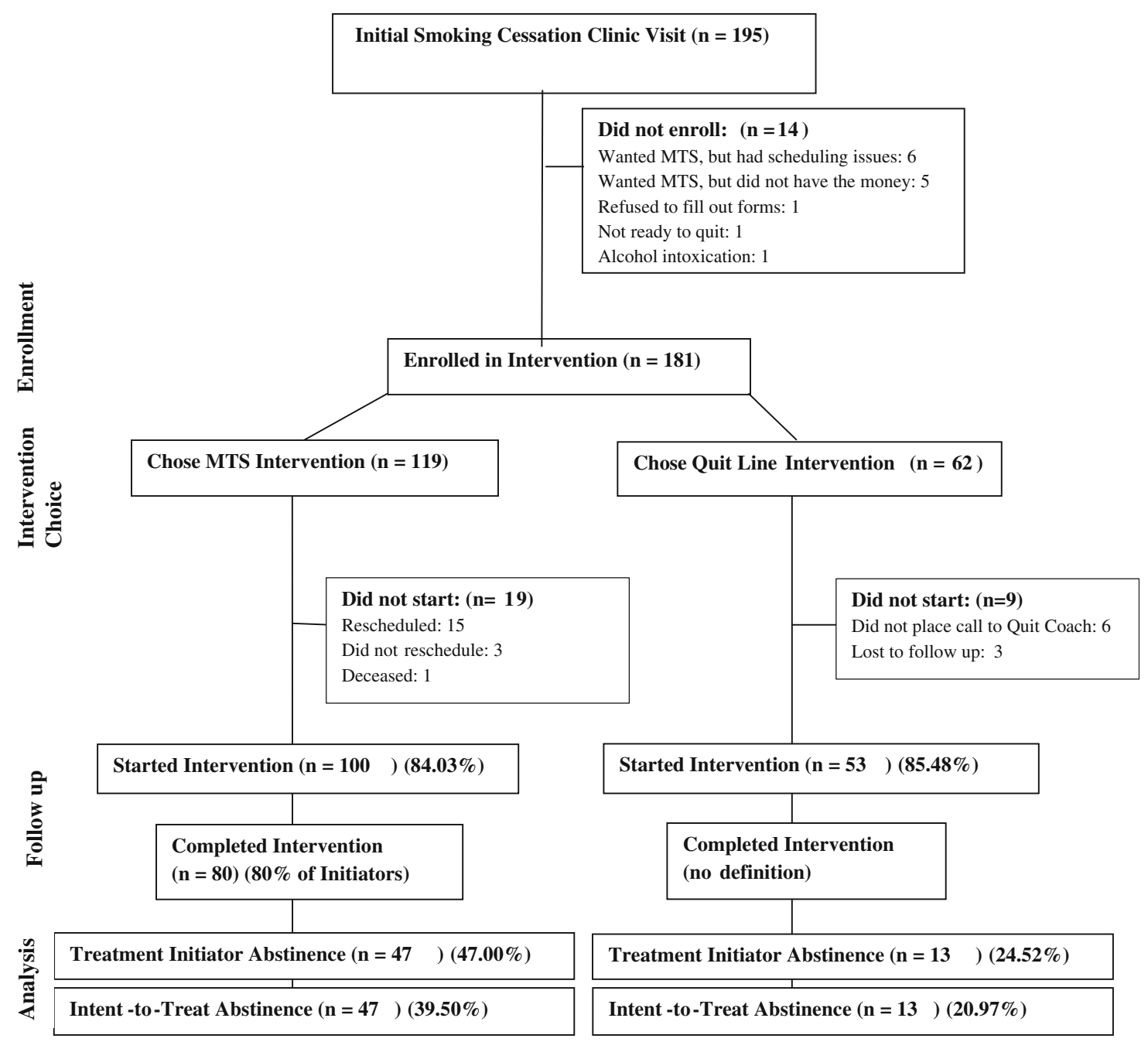

Fig. 1 Consort diagram

\section{Baseline Variables}

Analyses were conducted to determine whether baseline variables were associated with smoking abstinence. There was no difference between abstinent and relapsed participants on number of years smoked ( $p=.09$ ), number of cigarettes per day $(p=.76)$, gender $(p=.29)$, or race $(p=.13)$. Abstinent vs. relapsed participants did, however, differ on age (abstinent $=54.49$ years, relapsed $=50.00$ years, $t[178]=2.38$, $p=.02$ ) and education (beyond high school $=51.89 \%$, high school or less $=21.57 \%, \chi^{2}[1]=16.74, p<.001$ ). Binary logistic regression was used to compare intent-to-treat smoking abstinence rates between the MTS and WTQL groups while controlling for baseline covariates. In these models, differences in abstinence between MTS and WTQL remained significant when controlling for gender, age, race, baseline cigarettes per day, years smoked, and previous quit attempts $(p \mathrm{~s}<.05)$. The difference between MTS and WTQL was no longer significant, however, when controlling for education beyond high school $(p=.304)$.

\section{Treatment Adherence and Treatment-Based Predictors of Abstinence}

MTS treatment initiators attended an average of 7.17 out of 8 classes ( $\mathrm{SD}=1.12)$, with abstinent smokers attending more classes (7.39) than relapsed smokers (6.79) $(p=.02)$. WTQL treatment initiators completed an average of $1.93(\mathrm{SD}=1.43)$ Quit Coach calls. Differences were non-significant between abstinent and relapsed smokers on calls completed $(p=.41)$. Minutes meditated over 7 days assessed in the MTS group at the 2-week post-quit visit showed a mean of $13.82 \mathrm{~min}$ $(\mathrm{SD}=10.08)$ per day. Abstinent vs. relapsed participants showed a trend (non-significant) toward greater amount of time in daily meditation (abstinent $=15.34 \mathrm{~min}$, relapsed $=11.27 \mathrm{~min}, p=.09$ ). At the 2 weeks post-quit assessment visit, medication use was numerically higher in MTS (MTS $=78 \%$ and WTQL $=60 \%$ ) but failed to reach significance $(p=.08)$. Medication use did not predict abstinence in the full sample $(p=.23)$, or within-group MTS $(p=.17)$, or WTQL $(p=.93)$, although the WTQL group 
Table 1 Sample demographics

\begin{tabular}{|c|c|c|c|c|c|c|c|}
\hline \multirow[t]{2}{*}{ Variable } & \multicolumn{2}{|l|}{ Total $(n=181)$} & \multicolumn{2}{|l|}{$\operatorname{MTS}(n=119)$} & \multicolumn{2}{|l|}{$\mathrm{QL}(n=62)$} & \multirow[t]{2}{*}{$p$ value } \\
\hline & $n /$ mean (SD) & $\%$ & $n /$ mean $(\mathrm{SD})$ & $\%$ & n/mean (SD) & $\%$ & \\
\hline Age & $51.60(12.23)$ & & $51.60(12.46)$ & & $51.63(11.80)$ & & 0.987 \\
\hline Male & 64 & 35.36 & 38 & 31.93 & 26 & 41.94 & 0.241 \\
\hline Female & 117 & 64.64 & 81 & 68.07 & 36 & 58.06 & 0.241 \\
\hline Race/ethnicity & & & & & & & $<.001 * * *$ \\
\hline African-American & 18 & 9.94 & 5 & 4.20 & 13 & 20.97 & \\
\hline American Indian & 2 & 1.10 & 0 & 0.00 & 2 & 3.23 & \\
\hline Asian & 0 & 0.00 & 0 & 0.00 & 0 & 0.00 & \\
\hline Caucasian & 157 & 86.74 & 111 & 93.28 & 46 & 74.19 & \\
\hline Latino/Hispanic & 2 & 1.10 & 1 & 0.84 & 1 & 1.61 & \\
\hline Other & 2 & 1.10 & 2 & 1.68 & 0 & 0.00 & \\
\hline Education beyond high school & 78 & 43.09 & 68 & 57.14 & 10 & 16.13 & $<.001 * * *$ \\
\hline Drinks per week & $1.29(1.98)$ & & $1.57(2.27)$ & & $0.76(1.45)$ & & $0.011 *$ \\
\hline Cigs per day & $18.37(9.94)$ & & $17.74(8.40)$ & & $19.58(12.90)$ & & 0.249 \\
\hline Years smoked & $30.68(14.12$ & & $30.61(14.08)$ & & $30.82(14.20)$ & & 0.923 \\
\hline Quit attempts & $5.84(7.44)$ & & $5.71(4.60)$ & & $6.11(12.90)$ & & 0.761 \\
\hline
\end{tabular}

$* p<.05 ; * * p<.01 ; * * * p<.001$

(who received free patches from the WTQL) was more likely to use smoking cessation medications than the MTS group (Table 2). When controlling medication use, the difference between MTS and WTQL smoking abstinence remained significant $(p<.05)$ for both the ITT and treatment initiator samples.

\section{Discussion}

As an observational study, this trial is limited by the fact that participants choose their treatments (no randomization) and paid for medications and treatments. In addition, MTS required payment, whereas WTQL was free and provided free
NRT. These differences introduce multiple potential biases related to financial ability, medical literacy, time flexibility, and understanding of treatments and make a fair comparison between MTS and WTQL interventions impossible. For a comparison between MTS and various controls (including WTQL), please see randomized trials already conducted on these interventions (Brewer et al. 2011; Davis et al. 2013, 2014a, b; Vidrine et al. 2016).

This trial provides a different perspective through its naturalistic design with more robust ecological validity. The study was designed to provide insight into how these two interventions function in a clinical setting including information on intervention enrollment, attendance, and smoking abstinence. With this objective in mind, it is noteworthy that MTS and

Table 2 Medications

\begin{tabular}{|c|c|c|c|c|c|}
\hline \multirow[t]{2}{*}{ Medication } & \multicolumn{2}{|c|}{ MTS patients } & \multicolumn{2}{|c|}{ WTQL patients } & \multirow[t]{2}{*}{$p$ value } \\
\hline & $n$ & $\%$ & $n$ & $\%$ & \\
\hline Patch alone & 6 & 5.04 & 23 & 37.10 & $<.001$ \\
\hline Patch + immediate release NRT & 1 & 0.84 & 1 & 1.61 & .999 \\
\hline Patch + other & 0 & 0.00 & 1 & 1.61 & .739 \\
\hline Immediate release NRT alone & 2 & 1.68 & 1 & 1.61 & .999 \\
\hline Varenicline alone & 1 & 0.84 & 1 & 1.61 & .999 \\
\hline Bupropion alone & 3 & 2.52 & 0 & 0.00 & .517 \\
\hline None & 102 & 85.71 & 33 & 53.23 & $<.001$ \\
\hline Other & 4 & 3.36 & 2 & 3.23 & .999 \\
\hline Total & 119 & & 62 & & \\
\hline
\end{tabular}


WTQL produced very similar abstinence rates to those found in a recent RCT. Initiator analysis of smoking abstinence in the current study can be compared to an initiator analysis within a recent $\mathrm{RCT}$ that showed abstinence for $\mathrm{MTS}=45.8 \%$ and $\mathrm{WTQL}=25.4 \%$ at 4 weeks post-quit attempt (Davis et al. 2014a). In a clinical setting, we would expect to see decreased treatment effects overall compared to an RCT due to RCT procedures known to support treatment effects (e.g. exclusion for comorbidities, no payment for medications or treatment, close staff supervision). Unexpectedly, high abstinence rates in the current study might be explained by the fact that this study allowed patients to choose between the two interventions - potentially enhancing motivation, the cost-incentive structure may have increased adherence, or clinic-based participants in the current study may have been more motivated to quit smoking than participants enrolled in a study solely for research purposes. Even with differences in population and design, the similarity of the effects between MTS and WTQL in a clinic and an RCT suggests that the robustness of the MTS intervention itself transcends the impact of participation through clinical or research settings. A large treatment effect of MTS is not surprising given the intensity of MTS ( $24 \mathrm{~h}$ of total contact time), which easily becomes the most prominent aspect of treatment (as opposed to researcher contact, medication payment, etc.).

A high percentage $(92.8 \%)$ of those who came to the smoking cessation clinic also enrolled in the study, such that study results should have relatively good generalizability to clinic population. The study maintained naturalistic design elements with no procedures, study visits, or contact with study staff, such that study outcomes should reliably reflect clinic outcomes. MTS course initiation rate during the study period was lower than expected $(84.03 \%$ of those who enrolled and paid for MTS actually attended classes), although 15 of 19 who did not attend rescheduled to take the course after the study period. Because a majority of non-initiators rescheduled to take the course at a later time, treatment initiator analyses may be as accurate as intent-to-treat analyses for estimation of clinical outcomes. WTQL participants showed a similar initiation rate of $85.48 \%$. For the most part, these participants placed an observed call to the Quit Line Registration Specialist but did not complete a call with a Quit Coach. MTS should have greater barriers for initiating treatment, because it is a high-intensity intervention. These barriers appear to have been ameliorated by other factors, however, the most obvious ones being prior payment for the course and perhaps population differences (education, age) between groups.

This study allowed for a choice between MTS and WTQL with the finding that $65.75 \%$ chose to enroll in MTS vs. $34.25 \%$ who chose to enroll in the WTQL. It is noteworthy that a majority of participants chose MTS over WTQL. This might be unexpected because MTS was more intensive (took more time) and required payment up front. The finding that a high proportion of participants chose MTS may have been due to the fact that the Program Coordinator informed all patients that MTS had been found to be more effective in randomized trials. The exit interview with the Program Coordinator suggests that some participants did respond to information from prior research on intervention efficacy. This exit interview also indicated that the promise of full reimbursement for the course on completion appeared to make patients more willing to pay for the course. These findings are important to our field since we typically assume that regardless of efficacy, most patients would rather participate in behavioral treatment that is lowintensity and free vs. high-intensity and not free (Rennie et al. 2007). The finding should be understood in the context of the fact that the mean age of participants in this study was 51.6 with mean of 5.84 quit attempts, and it is possible that older smokers, or smokers with numerous failed quit attempts, may be most willing to participate in intensive treatment if they believe it will help them quit smoking.

Because the study allowed participants to choose between treatments, it was expected that there would be differences in baseline variables between groups, including variables that might impact abstinence. When baseline variables were included as covariates in models of smoking abstinence, all variables except for education did not affect between group (i.e. MTS vs. WTQL) abstinence differences. The fact that baseline education impacted group differences suggests that the observed differences in MTS and WTQL could have been driven by baseline differences between groups. Population differences between groups are a flaw inherent in naturalistic studies due to lack of randomization. These kinds of methodological challenges are to be expected as researchers embrace calls to test interventions in clinical settings through effectiveness and implementation studies (Dimidjian and Segal 2015). Future randomized trials on MTS would be helpful to further elucidate the impact of education level on treatment outcomes.

In this study, neither group was prescribed medications through the study or clinical program but was advised to obtain medications from their primary provider. Participants using the WTQL, however, received through nicotine patches in the mail after enrollment. This resulted in a greater number of WTQL vs. MTS participants using medications. The lower level use of medications by MTS did not affect differences in abstinence between the two groups in any analysis, but it is concerning. There is consensus among investigators now that medications should be used during smoking cessation attempts whenever possible (Fiore et al. 2008). Because of the low level of medication use in MTS when relying on primary provider prescriptions, we changed our clinic structure so that all clinic patients now see a prescriber (physician or mid-level provider) trained in tobacco use treatment for prescription of 
medications. Meriter Hospital and Duke University have both adopted this prescriber-centered model.

Studies have shown that the use of cost-incentive structures leads to better outcomes because patients are more willing to engage treatment if there is an imminent reward (Volpp et al. 2009). Evidence shows that people are more motivated to avoid losses than they are to seek gains (Kahneman and Tversky 1979) but are most motivated when both losses and gains (i.e. sticks and carrots) are involved (Halpern et al. 2015). MTS in this study was provided for a fee, but with the promise that a health-system-associated insurance provider would reimburse the full cost upon course completion. This presents a "carrot" and a "stick"-if an enrollee does not complete the MTS course, they lose their enrollment fee, and if they complete the course, however, their enrollment fee is refunded. This cost-incentive pay structure was associated with a high rate of course completion in a course with a high rate of abstinence (65.3\%) among course completers. From the perspective of the insurance provider, this is an advantageous return on a relatively small payment and provides substantial advantages over models in which the health system pays to make smoking cessation services available to all patients, but only a fraction of patients use these services (An et al. 2010). This may be most advantageous to contemporary medical systems (HMOs and ACOs) in which the provider assumes financial liability for health outcomes of their patients (Madison et al. 2013). A growing proportion of smokers with high dependence, stress, or other comorbidities will need more intensive treatment to achieve abstinence. Due to the profound impact of smoking on health, it would be wise for health systems, especially those financially tied to health outcomes, to consider the additional use of more intensive behavioral smoking cessation treatments and payment structures that incentivize attendance.

\section{Limitations}

Limitations of this study included those found in any naturalistic observational study - self-selection of intervention groups led to population differences between groups, which made isolation of treatment effects impossible. Other problems existed as well-medication use, though not a predictor of outcomes, varied widely across subjects, the follow-up period was brief, and the lack of standardized self-report measures undermined any exploration of mechanism. The study, however, was not conducted on its own, but within an iterative series of studies on MTS. The purpose of this study was to provide ecological validity through naturalistic observational design for a treatment that has already been tested and found effective within randomized trials. Within this context, the principal finding of this study was that MTS, when provided in a clinical setting showed outcomes similar to those in randomized trials.
Author Contributions JD: Secured grant funding for the study, designed and executed the study, oversaw data collection and analysis, and primary manuscript writer.

SG: Conducted statistical analyses and helped write the manuscript.

KA: Conducted day-to-day operations of the study, collected data, and helped prepare methods section of manuscript.

RS: Collaborated in manuscript preparation, tables, figures, copy editing, and reference checks.

DL: Conducted data cleaning, secondary statistical analysis, and manuscript preparation and editing.

EK: Collaborated in manuscript preparation for background section, constructed tables, figures, and copy editing.

\section{Compliance with Ethical Standards}

Funding The study was funded through Meriter Foundation Research and Education Grant no. 477.

Ethical Approval All procedures performed in studies involving human participants were in accordance with the ethical standards of the institutional and national research committee and with the 1964 Helsinki declaration and its later amendments or comparable ethical standards. The study was approved by the Meriter Hospital Institutional Review Board (IRB) with University of Wisconsin IRB reciprocity.

Informed Consent Informed consent was obtained from all individual participants included in the study.

Conflict of Interest Dr. James Davis has received research funding from Pfizer. Dr. James Davis declares that he has no conflict of interest. Mr. Simon Goldberg declares that he has no conflict of interest. Ms. Kelly Bodoh declares that she has no conflict of interest. Ms. Rachel Silver declares that she has no conflict of interest. Ms. Emily Kragel declares that she has no conflict of interest. Mr. Delaney Lagrew declares that he has no conflict of interest.

\section{References}

Alberg, A. J., Shopland, D. R., \& Cummings, K. M. (2014). The 2014 Surgeon General's report: commemorating the 50th anniversary of the 1964 report of the Advisory Committee to the US Surgeon General and updating the evidence on the health consequences of cigarette smoking. American Journal of Epidemiology, 179(4), 403412. doi:10.1093/aje/kwt335.

An, L. C., Betzner, A., Schillo, B., Luxenberg, M. G., Christenson, M., Wendling, A., et al. (2010). The comparative effectiveness of clinic, work-site, phone, and web-based tobacco treatment programs. Nicotine \& Tobacco Research, 12(10), 989-996. doi:10.1093/ntr/ ntq133.

Annamalai, A., Singh, N., \& O’Malley, S. S. (2015). Smoking use and cessation among people with serious mental illness. The Yale Journal of Biology and Medicine, 88(3), 271-277.

Beck, A. T. (1979). Cognitive therapy of depression. New York: Guilford Press.

Brandon, T. H. (2001). Behavioral tobacco cessation treatments: yesterday's news or tomorrow's headlines? Journal of Clinical Oncology, 19(18), 64S-68S.

Brewer, J. A., Mallik, S., Babuscio, T. A., Nich, C., Johnson, H. E., Deleone, C. M., et al. (2011). Mindfulness training for smoking cessation: results from a randomized controlled trial. Drug Alcohol Dependendence, 119(1-2), 72-80. doi:10.1016/j.drugalcdep.2011. 05.027. 
Brewer, J. A., Elwafi, H. M., \& Davis, J. H. (2013). Craving to quit: psychological models and neurobiological mechanisms of mindfulness training as treatment for addictions. Psychology of addictive behaviors: journal of the Society of Psychologists in Addictive Behaviors, 27(2), 366-379. doi:10.1037/a0028490.

Bricker, J., \& Tollison, S. (2011). Comparison of motivational interviewing with acceptance and commitment therapy: a conceptual and clinical review. Behavioural and Cognitive Psychotherapy, 39(5), 541-559. doi:10.1017/s1352465810000901.

Brown, R. A., Burgess, E. S., Sales, S. D., Whiteley, J. A., Evans, M. D., \& Miller, I. W. (1995). Reliability and validity of a smoking timeline follow-back interview. Psychology of Addictive Behavior, 12(2), 101-112.

Centers for Disease Control and Prevention. (2008). Smokingattributable mortality, years of potential life lost, and productivity losses-United States, 2000-2004. Morbidity and Mortality Weekly Report, 57(45), 1226.

Centers for Disease Control and Prevention. (2011). Quitting smoking among adults: United States, 2001-2010. Morbidity and Mortality Weekly Report, 60(44), 1513-1519.

Centers for Disease Control and Prevention. (2013). Vital signs: current cigarette smoking among adults aged $\geq 18$ years with mental illness-United States, 2009-2011. Morbidity and Mortality Weekly Report, 62(5), 81-87.

Chaiton, M. O., Cohen, J. E., \& Frank, J. (2008). Population health and the hardcore smoker: Geoffrey Rose revisited. Journal of Public Health Policy, 29(3), 307-318. doi:10.1057/jphp.2008.14.

Chaiton, M., Diemert, L., Cohen, J. E., Bondy, S. J., Selby, P., Philipneri, A., \& Schwartz, R. (2016). Estimating the number of quit attempts it takes to quit smoking successfully in a longitudinal cohort of smokers. British Medical Journal, 6(6), e011045. doi:10.1136/ bmjopen-2016-011045.

Cokkinides, V., Bandi, P., McMahon, C., Jemal, A., Glynn, T., \& Ward, E. (2009). Tobacco control in the United States - recent progress and opportunities. CA: a Cancer Journal for Clinicians, 59(6), 352-365. doi:10.3322/caac.20037.

Creswell, J. D., Way, B. M., Eisenberger, N. I., \& Lieberman, M. D. (2007). Neural correlates of dispositional mindfulness during affect labeling. Psychosomatic Medicine, 69(6), 560-565. doi:10.1097/ PSY.0b013e3180f6171f.

Davis, J. M., Fleming, M. F., Bonus, K. A., \& Baker, T. B. (2007). A pilot study on mindfulness based stress reduction for smokers. $B M C$ Complementary and Alternative Medicine, 7, 2. doi:10.1186/14726882-7-2.

Davis, J. M., Mills, D. M., Stankevitz, K. A., Manley, A. R., Majeskie, M. R., \& Smith, S. S. (2013). Pilot randomized trial on mindfulness training for smokers in young adult binge drinkers. $B M C$ Complementary and Alternative Medicine, 13, 215. doi:10.1186/ 1472-6882-13-215.

Davis, J. M., Goldberg, S. B., Anderson, M. C., Manley, A. R., Smith, S. S., \& Baker, T. B. (2014a). Randomized trial on mindfulness training for smokers targeted to a disadvantaged population. Substance Use \& Misuse, 49(5), 571-585. doi:10.3109/10826084.2013. 770025.

Davis, J. M., Manley, A. R., Goldberg, S. B., Smith, S. S., \& Jorenby, D. E. (2014b). Randomized trial comparing mindfulness training for smokers to a matched control. Journal of Substance Abuse Treatment, 47(3), 213-221. doi:10.1016/j.jsat.2014.04.005.

Dimidjian, S., \& Segal, Z. V. (2015). Prospects for a clinical science of mindfulness-based intervention. American Psychologist, 70(7), 593.

Elwafi, H. M., Witkiewitz, K., Mallik, S., Thornhill, T. A., \& Brewer, J. A. (2013). Mindfulness training for smoking cessation: moderation of the relationship between craving and cigarette use. Drug and Alcohol Dependence, 130, 222-229. doi:10.1016/j.drugalcdep. 2012.11.015.
Fiore, M. C., Jaen, C. R., Baker, T. B., Bailey, W. C., Benowitz, N. L., Curry, S. J., et al. (2008). Treating tobacco use and dependence: an introduction to the US Public Health Service Clinical Practice Guideline. American Journal of Preventative Medicine, 35(2), $158-176$.

Garland, E. L., Froeliger, B., \& Howard, M. O. (2013). Mindfulness training targets neurocognitive mechanisms of addiction at the attention-appraisal-emotion interface. Frontiers in Psychiatry, 4, 173. doi:10.3389/fpsyt.2013.00173.

Gifford, E. V., Kohlenberg, B. S., Hayes, S. C., Pierson, H. M., Piasecki, M. P., Antonuccio, D. O., \& Palm, K. M. (2011). Does acceptance and relationship focused behavior therapy contribute to bupropion outcomes? A randomized controlled trial of functional analytic psychotherapy and acceptance and commitment therapy for smoking cessation. Behavior Therapy, 42(4), 700-715.

Goldberg, S. B., Manley, A. R., Smith, S. S., Greeson, J. M., Russell, E., Van Uum, S., et al. (2014). Hair cortisol as a biomarker of stress in mindfulness training for smokers. Journal of Alternative and Complementary Medicine, 20(8), 630-634. doi:10.1089/acm.2014. 0080 .

Goodwin, R. D., Keyes, K. M., \& Hasin, D. S. (2009). Changes in cigarette use and nicotine dependence in the United States: evidence from the 2001-2002 wave of the National Epidemiologic Survey of alcoholism and related conditions. American Journal of Public Health, 99(8), 1471-1477. doi:10.2105/AJPH.2007.127886.

Grossman, P., Niemann, L., Schmidt, S., \& Walach, H. (2004). Mindfulness-based stress reduction and health benefits. A metaanalysis. Journal of Psychosomatic Research, 57(1), 35-43. doi: 10.1016/S0022-3999(03)00573-7.

Halpern, S. D., French, B., Small, D. S., Saulsgiver, K., Harhay, M. O., Audrain-McGovern, J., et al. (2015). Randomized trial of four financial-incentive programs for smoking cessation. New England Journal of Medicine, 372(22), 2108-2117. doi:10.1056/ NEJMoa1414293.

Hofmann, S. G., Sawyer, A. T., Witt, A. A., \& Oh, D. (2010). The effect of mindfulness-based therapy on anxiety and depression: a metaanalytic review. Journal of Consulting and Clinical Psychology, 78(2), 169-183. doi:10.1037/a0018555.

Hughes, J. R. (2011). The hardening hypothesis: is the ability to quit decreasing due to increasing nicotine dependence? A review and commentary. Drug and Alcohol Dependence, 117(2-3), 111-117. doi:10.1016/j.drugalcdep.2011.02.009.

Ip, D. T., Cohen, J. E., Bondy, S. J., Chaiton, M. O., Selby, P., Schwartz, R., et al. (2012). Do components of current 'hardcore smoker' definitions predict quitting behaviour? Addiction, 107(2), 434-440. doi: 10.1111/j.1360-0443.2011.03674.x.

Irvin, J. E., Hendricks, P. S., \& Brandon, T. H. (2003). The increasing recalcitrance of smokers in clinical trials II: Pharmacotherapy trials. Nicotine \& Tobacco Research, 5(1), 27-35.

Kabat-Zinn, J., \& Hanh, T. N. (1990). Full catastrophe living: using the wisdom of your body and mind to face stress, pain, and illness. New York: Delta Trade Paperbacks.

Kahneman, D., \& Tversky, A. (1979). Prospect theory: an analysis of decision under risk. Econometrica, 47(2), 263-292. doi:10.2307/ 1914185.

Kobinsky, K. H., Redmond, L. A., Smith, S. S., Yepassis-Zembrou, P. L., \& Fiore, M. C. (2010). The Wisconsin Tobacco Quit Line's fax to quit program: participant satisfaction and effectiveness. Wisconsin Medical Journal, 109(2), 79-84.

Koszycki, D., Benger, M., Shlik, J., \& Bradwejn, J. (2007). Randomized trial of a meditation-based stress reduction program and cognitive behavior therapy in generalized social anxiety disorder. Behvaior Research and Therapy, 45(10), 2518-2526. doi:10.1016/j.brat. 2007.04.011.

Lai, D. T., Cahill, K., Qin, Y., \& Tang, J. L. (2010). Motivational interviewing for smoking cessation. Cochrane Database of 
Systematic Reviews, 20(1), CD006936. doi:10.1002/14651858. CD006936.pub2.

Madison, K., Schmidt, H., \& Volpp, K. G. (2013). Smoking, obesity, health insurance, and health incentives in the affordable care act. Journal of American Medical Association, 310(2), 143-144. doi: 10.1001/jama.2013.7617.

McLeod, S. A. (2015). Observation methods. Retrieved from http://www. simplypsychology.org/observation.htmlx. Accessed April 26, 2015.

Moulton, L. H. (2004). Covariate-based constrained randomization of group-randomized trials. Clinical Trials, 1(3), 297-305.

National institute for Health and Care Excellence. (2010). How to stop smoking in pregnancy and following childbirth. 1-58.

Oikonomou, M. T., Arvanitis, M., \& Sokolove, R. L. (2016). Mindfulness training for smoking cessation: a meta-analysis of randomizedcontrolled trials. Journal of Health Psychology, 1-10. doi:10.1177/ 1359105316637667.

R Development Core Team. (2011). $R$ : A language and environment for statistical computing. Vienna: R Foundation for Statistical Computing.

Rennie, T. W., Bothamley, G. H., Engova, D., \& Bates, I. P. (2007). Patient choice promotes adherence in preventive treatment for latent tuberculosis. European Respiratory Journal, 30(4), 728-735. doi: 10.1183/09031936.00034007.

Rogojanski, J., Vettese, L. C., \& Antony, M. M. (2011). Coping with cigarette cravings: comparison of suppression versus mindfulnessbased strategies. Mindfulness, 2(1), 14-26.

Segal, Z. V., Williams, M. J., \& Teasdale, J. D. (2002). Mindfulness-based cognitive therapy for depression (2nd ed.). New York: Guilford Press.

Sibbald, B., \& Roland, M. (1998). Understanding controlled trials. Why are randomised controlled trials important? British Medical Journal, 316(7126), 201.

Song, J. W., \& Chung, K. C. (2010). Observational studies: cohort and case-control studies. Plastic and Reconstructive Surgery, 126(6), 2234-2242. doi:10.1097/PRS.0b013e3181f44abc.

Stead, L. F., Perera, R., Bullen, C., Mant, D., \& Lancaster, T. (2008). Nicotine replacement therapy for smoking cessation. Cochrane Database of System Reviews, 3, CD000146. doi:10.1002/ 14651858.CD000146.pub3.

Stolberg, H. O., Norman, G., \& Trop, I. (2004). Randomized controlled trials. American Journal of Roentgenology, 183(6), 1539-1544. doi: 10.2214/ajr.183.6.01831539.
Teasdale, J. D., Segal, Z., \& Williams, J. M. (1995). How does cognitive therapy prevent depressive relapse and why should attentional control (mindfulness) training help? Behaviour Research and Therapy, 33(1), 25-39.

Vidrine, J. I., Spears, C. A., Heppner, W. L., Reitzel, L. R., Marcus, M. T., Cinciripini, P. M., et al. (2016). Efficacy of Mindfulness-Based Addiction Treatment (MBAT) for smoking cessation and lapse recovery: a randomized clinical trial. Journal of Consulting and Clinical Psychology, 84(9), 824-838. doi:10.1037/ccp0000117.

Volpp, K. G., Troxel, A. B., Pauly, M. V., Glick, H. A., Puig, A., Asch, D. A., et al. (2009). A randomized, controlled trial of financial incentives for smoking cessation. New England Journal of Medicine, 360(7), 699-709. doi:10.1056/NEJMsa0806819.

Way, B. M., Creswell, J. D., Eisenberger, N. I., \& Lieberman, M. D. (2010). Dispositional mindfulness and depressive symptomatology: correlations with limbic and self-referential neural activity during rest. Emotion, 10(1), 12-24.

Weisberg, H. I., Hayden, V. C., \& Pontes, V. P. (2009). Selection criteria and generalizability within the counterfactual framework: explaining the paradox of antidepressant-induced suicidality? Clinical Trials, 6(2), 109-118. doi:10.1177/1740774509102563.

Weiss, N. S., Koepsell, T. D., \& Psaty, B. M. (2008). Generalizability of the results of randomized trials. Archives of Internal Medicine, 168(2), 133-135. doi:10.1001/archinternmed.2007.30.

Westbrook, C., Creswell, J. D., Tabibnia, G., Julson, E., Kober, H., \& Tindle, H. A. (2013). Mindful attention reduces neural and selfreported cue-induced craving in smokers. Social Cognitive Affective Neuroscience, 8(1), 73-84. doi:10.1093/scan/nsr076.

Whitfield, H. J. (2006). Towards case-specific applications of mindfulness-based cognitive-behavioural therapies: a mindfulnessbased rational emotive behaviour therapy. Counselling Psychology Quarterly, 19(2), 205-217. doi:10.1080/09515070600919536.

Witkiewitz, K., Bowen, S., Harrop, E. N., Douglas, H., Enkema, M., \& Sedgwick, C. (2014). Mindfulness-based treatment to prevent addictive behavior relapse: theoretical models and hypothesized mechanisms of change. Substance Use \& Misuse, 49(5), 513-524. doi:10. 3109/10826084.2014.891845.

Wolpe, J. (1990). The practice of behavior therapy (3rd ed.). New York: Pergamon.

Woolf, S. H. (2008). The meaning of translational research and why it matters. Journal of American Medical Association, 299(2), 211213. doi:10.1001/jama.2007.26. 